HEART REVIEW

\title{
Origin of symptoms in chronic heart failure
}

A L Clark

Heart 2006;92:12-16. doi: 10.1136/hrt.2005.066886

Skeletal muscle abnormalities are highly prevalent in chronic heart failure and are associated with an increase in the ergoreflex, a muscle reflex stimulated by work done. Stimulation of the ergoreflex results in increased ventilation and contributes to the increased sympathetic activation of the heart failure syndrome. The origin of the skeletal myopathy is related to a chronic imbalance between catabolic and anabolic processes, presumably as a consequence of chronic haemodynamic stress. Symptoms arise from the skeletal myopathy, causing the sensation of fatigue and contributing to the sensation of breathlessness as the myopathy affects respiratory muscle. Ergoreflex activation causes a greater ventilatory response to exercise than normal, contributing to the sensation of breathlessness.

Correspondence to: Dr Andrew L Clark Academic Cardiology Castle Hill Hospital, Castle Road, Cottingham, Hull HU16 5JQ, UK; a.l.clark@ hull.ac.uk

Accepted 13 August 2005 Published Online First 13 September 2005
$\mathrm{T}$ o have a diagnosis of chronic heart failure, a person has to have symptoms compatible with the diagnosis. In the absence of symptoms, the patient has "asymptomatic left ventricular dysfunction". One of the surprising features of chronic heart failure caused by systolic left ventricular dysfunction, at least, is that patients with apparently very poor left ventricular function can have very little in the way of symptoms. Others with only apparently minor degrees of left ventricular dysfunction can be highly asymptomatic. ${ }^{1}$

The dominant symptoms of chronic heart failure are breathlessness and fatigue on exertion. A traditional view of the pathophysiology of the symptoms runs as follows (fig 1): firstly, the failing heart has an impaired response to exercise. In turn, this leads to failure to perfuse the exercising muscle adequately; the unhappy skeletal muscle signals the brain, and this sensation is interpreted as fatigue. Secondly, the failing heart requires an ever higher left ventricular filling pressure to maintain output, particularly during exertion; the filling pressure can rise high enough to cause either stiff lungs or even transudation of fluid into the alveoli. This causes breathlessness.

This sort of model suggests that there are two groups of patients with different exertional responses; however, we found that regardless of the symptom experienced by the patient, the metabolic and ventilatory responses to exercise were the same, suggesting a unifying underlying explanation for the generation of symptoms. ${ }^{2}$ The patient interprets the symptoms as breathlessness or fatigue variably-for example, more rapidly incremental tests are likely to be terminated by breathlessness, whereas a slower test, although eliciting the same exercise performance, is more likely to be terminated by fatigue. Cycle exercise is more often stopped by fatigue than by breathlessness, compared with treadmill exercise, even when the same level of exercise is performed. ${ }^{3}$

\section{MEASURING EXERCISE}

Symptoms of their nature are subjective. A variety of scores has been used with the New York Heart Association classification of symptoms being nearly universally used to describe the symptoms of patients with heart failure. For symptoms during exercise testing, some version of the linear Borg scale is most commonly used.

To get an objective measurement of exercise performance, some form of exercise testing is necessary. Corridor walk tests, particularly the six minute walk test, are commonly used and are cheap and simple to administer. ${ }^{4}$ To explore the pathophysiology of exercise limitation in greater detail, however, incremental testing with metabolic gas exchange measurement is most useful. A subject exercises to exhaustion, breathing through a tight fitting mask or mouthpiece, and the expired air is collected and analysed. Several variables are derived:

- Peak oxygen consumption $\left(\dot{\mathrm{V}}_{2}\right)$-that is, the maximum rate of oxygen consumption achieved, used as an index of exercise performance;

- The slope of the relation between ventilation and carbon dioxide production $\left(\dot{\mathrm{V}} \mathrm{E} / \dot{\mathrm{V}} \mathrm{CO}_{2}\right.$ slope) as an index of the ventilatory response to exercise;

- The respiratory exchange ratio (the ratio of $\dot{\mathrm{V}} \mathrm{CO}_{2}$ to $\dot{\mathrm{V}}_{2}$ ).

Peak $\dot{\mathrm{V}}_{2}$ is an artificial variable in that very few patients are challenged by the need to perform maximal exercise in daily life, yet it is reproducible, highly predictive of survival, and useful in selecting those patients with most to gain from heart transplantation.

The $\dot{\mathrm{V}} / \dot{\mathrm{V}}_{\mathrm{CO}}$ slope is highly linear, and the slope is increased with increasing severity of heart failure-that is, for any given level of carbon dioxide production, the ventilatory response is increased with worsening heart failure symptoms (fig 2). Peak $\dot{\mathrm{V}}_{2}$ and the

Abbreviations: $\mathrm{PaCO}_{2}$, arterial carbon dioxide tension; $\dot{\mathrm{V}} \mathrm{E} / \dot{\mathrm{V}} \mathrm{CO}_{2}$, relation between ventilation and carbon dioxide production; $V_{D} / V_{T}$, dead space as a fraction of tidal volume; $\dot{\mathrm{V}}_{2}$, oxygen consumption 


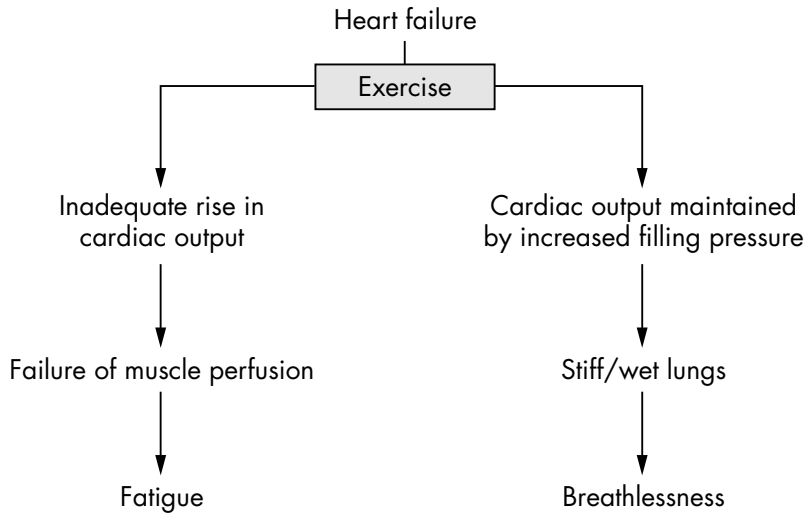

Figure 1 Haemodynamic model of heart failure symptoms.

$\dot{\mathrm{V}} \mathrm{E} / \dot{\mathrm{V}} \mathrm{CO}_{2}$ slope are negatively correlated with each other. ${ }^{6}$

The respiratory exchange ratio is an index of how "maximal" the test has been: at rest, the respiratory exchange ratio is around 0.7 and rises during exertion to greater than 1.0. In normal subjects, the respiratory exchange ratio can rise to 1.4 or higher but, in practice, a value of over 1.05 is taken to indicate maximum exertion.

\section{CENTRAL HAEMODYNAMIC FUNCTION}

If the haemodynamic model is correct, then there should be some relation between cardiac performance and exercise performance. However, this is not the case. Many studies have shown that there is no correlation between indices of cardiac function at rest and during exercise performance. ${ }^{78}$ More tellingly, acute changes in haemodynamic functions, either pharmacological or by cardiac transplantation, do not affect exercise performance. ${ }^{9} 10$

In normal subjects, peak exercise performance does seem to be related to peak cardiac output. However, in patients with heart failure this does not seem to be the case. A key observation is that during maximal leg exercise if an additional arm exercise load is imposed then in patients with heart failure (in contrast to normal subjects) $\dot{\mathrm{V}}_{2}$ (and cardiac output) increases further. ${ }^{11}$

Some work has implicated the pulmonary circulation in limiting exercise including pulmonary vascular resistance and pulmonary artery wedge pressure. ${ }^{12}$ Right ventricular ejection fraction has been proposed as a potential limiting factor. We found, however, that even in a group of patients with the Fontan circulation (thus having no right ventricular contribution to the circulation at all) exercise performance could be normal and that peak $\dot{\mathrm{V}}_{2}$ and the $\dot{\mathrm{V}} \mathrm{E} / \dot{\mathrm{V}}_{\mathrm{CO}_{2}}$ slope were still negatively related. ${ }^{8}$

\section{THE LUNGS}

Much attention has focused on the lungs as a possible source of symptoms. The $\dot{\mathrm{V}} \mathrm{E} / \dot{\mathrm{V}}_{\mathrm{CO}_{2}}$ slope increases from the outset of exercise and implies that some abnormality in the lungs may be responsible. The ratio between ventilation and carbon dioxide production is described by the equation $\dot{\mathrm{V}} \mathrm{E} / \mathrm{V}_{\mathrm{CO}_{2}}=$ $863 / \mathrm{PaCO}_{2} \times(1-\mathrm{VD} / \mathrm{VT})$, where 863 is a constant, $\mathrm{PaCO}_{2}$ is the arterial carbon dioxide tension, and $\mathrm{VD} / \mathrm{VT}$ is dead space as a fraction of tidal volume.

Most studies of patients with chronic heart failure have shown that $\mathrm{PaCO}_{2}$ is, if anything, decreased compared with normal, ${ }^{13}$ implying that the increase in the $\dot{\mathrm{V}} \mathrm{E} / \dot{\mathrm{V}} \mathrm{CO}_{2}$ slope must be due to an increase in dead space ventilation. ${ }^{14}$ How might this arise? Dead space comprises alveoli that are ventilated, but not perfused, and the failing heart may be causing some difficulty with lung perfusion. Many patients

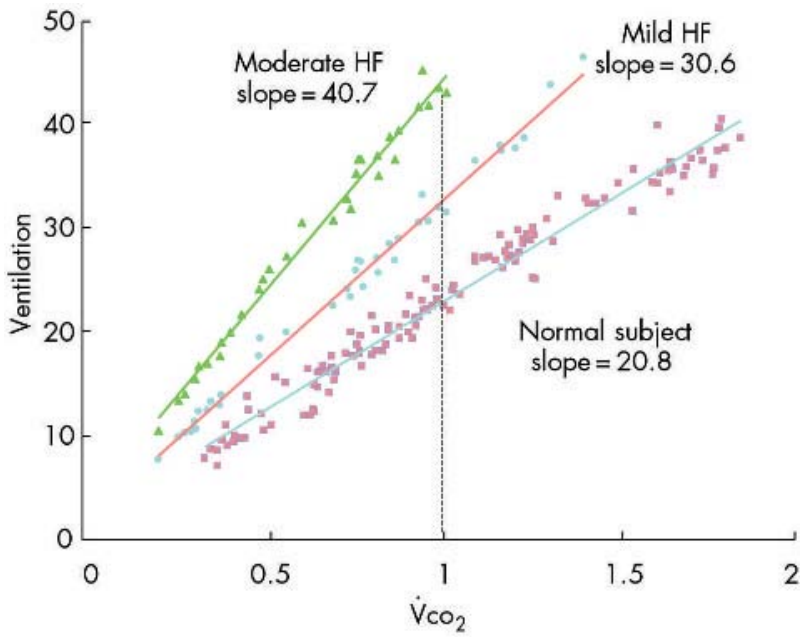

Figure 2 Ventilation/carbon dioxide production $\left(\dot{\mathrm{V}} \mathrm{E} / \mathrm{V} \mathrm{CO}_{2}\right)$ slope in heart failure (HF). Note that the relation between $\mathrm{V} E$ and $\dot{V} \mathrm{CO}_{2}$ remains linear but that the slope increases with worsening heart failure. Thus, for a $\dot{\mathrm{V}} \mathrm{CO}_{2}$ of $1 \mathrm{l} / \mathrm{min}$, a normal subject has to ventilate at $22 \mathrm{l} / \mathrm{min}$ and the patient with moderate heart failure ventilates at $42 \mathrm{l} / \mathrm{min}$.

have abnormalities of lung function as assessed by spirometry, and more severely symptomatic patients have impaired diffusion at the level of the alveolar-capillary membrane. ${ }^{15}$

Against this notion, we have shown that, although VD/VT was higher at submaximal exertion in patients than in controls (although lower than at rest), absolute dead space ventilation was higher at peak exercise in controls than in patients, as was absolute dead space in each breath (measured in litres, not as a fraction of tidal volume). ${ }^{16} \mathrm{~A}$ further observation is that perfusion to the lung apices appears to be increased in patients with heart failure at rest and does not change with exertion. ${ }^{17}$ Additionally, the potential signal being detected by the respiratory centre and increasing ventilation has to be considered. There is no "dead space receptor" and blood gas tensions are normal or supranormal in exercising patients with heart failure. ${ }^{13}$ Indeed, the more limited the patient is in terms of increased $\dot{\mathrm{V}} \mathrm{E} / \dot{\mathrm{V}} \mathrm{CO}_{2}$ slope and reduced peak $\dot{\mathrm{V}}_{2}$, the lower is the $\mathrm{PaCO}_{2}$ at peak exercise. ${ }^{16}$

These findings cannot exclude the possibility that there is some abnormality in the oscillation of blood gas tensions, perhaps, that is sensed, but they do suggest that it is not the lungs causing exercise limitation. Some of the lung abnormalities may even be a response to an excessive ventilatory stimulus arising elsewhere. If there were such a stimulus, then the effect may be to drive $\mathrm{PaCO}_{2}$ too low. Dead space may perhaps rise to prevent this happening.

\section{SKELETAL MUSCLE}

From where can the ventilatory stimulus be arising? Skeletal muscle is abnormal in patients with heart failure from an early stage in the progression of the disease. Muscle bulk is lost, and exercise capacity is related to both muscle strength and bulk. ${ }^{18}$ Muscle strength is reduced, as is endurance. ${ }^{19} 20$ From the patient's point of view, the ability to perform repeated submaximal exercise is more important than peak force generation, and early quadriceps fatiguability has been reported. ${ }^{20}$ The reduction in endurance correlates with exercise performance.

Fatigue is independent of acute changes in blood flow and of central factors. ${ }^{20}$ Fatiguability has been shown in a very small muscle group in which blood flow is most unlikely to 
be limited by cardiac reserve, suggesting that intrinsic muscle factors mediate fatigue. ${ }^{19}$

Skeletal muscle is histologically abnormal with a shift towards type II muscle fibres. ${ }^{21}$ (Type II fibres are fast twitch, anaerobic fibres.) Mitochondrial structure is abnormal, with a reduction in volume of the cristae, and enzyme content is reduced, particularly of the enzymes of the Krebs cycle and in the oxidative chain. ${ }^{22}$ The changes in muscle structure and ultrastructure are reflected in changes in muscle metabolism. Magnetic resonance spectroscopy can be used to examine intracellular phosphate metabolism, which has been shown to be abnormal in chronic heart failure with more rapid depletion of phosphocreatine and early acidosis than normal. ${ }^{23}$

It is easy to picture how these abnormalities can lead to the sensation of fatigue. Breathlessness may arise from similar changes seen in the muscles of respiration, but this does not explain the increase in the $\dot{\mathrm{V}} \mathrm{E} / \dot{\mathrm{V}}_{\mathrm{CO}_{2}}$ slope. Abnormal skeletal muscle signalling does, however, present a unifying hypothesis and helps explain other features of the heart failure syndrome.

\section{THE ERGOREFLEX}

Ergoreceptors are muscle receptors sensitive to work performed. Their stimulation during exercise results in increased ventilation and sympathetic activation (the ergoreflex). The stimulus is in part sensitive to work performed by each unit of muscle mass. This effect can be seen in normal subjects, where the $\dot{\mathrm{V}} / \dot{\mathrm{V}}_{\mathrm{CO}}$ slope is considerably greater when arms are used than when legs are used to perform the same external workload. ${ }^{24}$

Piepoli et $a l^{25}$ showed how these receptors were more active in patients with heart failure and that the increased ventilatory response to exercise was proportional to the ergoreflex activity (fig 3). The signal is due to metabolic stimulation of receptors rather than being merely a response to movement. Possible stimuli for initiating the ergoreflex are local release of prostaglandins, potassium, and hydrogen ion. The ergoreflex is a potential target for therapy and not just an abstract conception: Piepoli et $a^{25}$ further showed that the ergoreflex contribution to ventilation could be reduced by exercise training.
A unifying hypothesis, then, is that skeletal muscle becomes abnormal in chronic heart failure. In turn, this leads to abnormal muscle performance during exercise, objectively seen as reduced strength and endurance and subjectively felt as the sensation of fatigue. The abnormal muscle causes an enhanced ergoreflex response to exercise, which causes an excessive ventilatory response, seen objectively as an increase in the $\dot{\mathrm{V}} \mathrm{E} / \dot{\mathrm{V}}_{\mathrm{CO}}$ slope and interpreted subjectively as the sensation of breathlessness.

This explanation for the pathophysiology of symptom generation in heart failure ties together the two principle symptoms of heart failure and explains other aspects of the heart failure state. For example, the sympathetic activation that is such a prominent feature of heart failure is commonly supposed to be caused by increased baroreflex activity in response to falls in blood pressure. In fact, baroreflex activity is reduced in chronic heart failure. Stimulation of the ergoreflex, however, causes sympathetic activation. Chronic overactivity of the ergoreflex may be responsible both for chronic sympathetic activation and for downregulation of the baroreceptors.

\section{ORIGINS OF MUSCLE CHANGES}

Skeletal muscle changes must ultimately be related to heart failure itself, and the obvious candidate is decreased peripheral perfusion. Oxygen saturation in veins draining exercising muscle of patients with heart failure can be very low indeed, suggesting that muscular exercise is limited by the failure of the circulation to deliver oxygen to the tissues rather than by failure of the tissues to extract oxygen. ${ }^{26}$

Peripheral resistance is greatly increased in patients with heart failure, but the relation between blood flow and exercise capacity is complex. Acute changes in blood flow induce no change in lactate production at matched workload, highlighting the possible distinction between "nutritive flow" and mere blood flow. Some patients have normal blood flow but abnormal metabolism. ${ }^{27}$

Although some of the changes of chronic heart failure are similar to the effects of de-training in normal subjects, disuse is unlikely to be the only contributor to muscle changes. In normal subjects undergoing de-training, there is little evidence of the fibre type shift seen in heart failure and, as the heart failure muscle changes are seen in small muscles
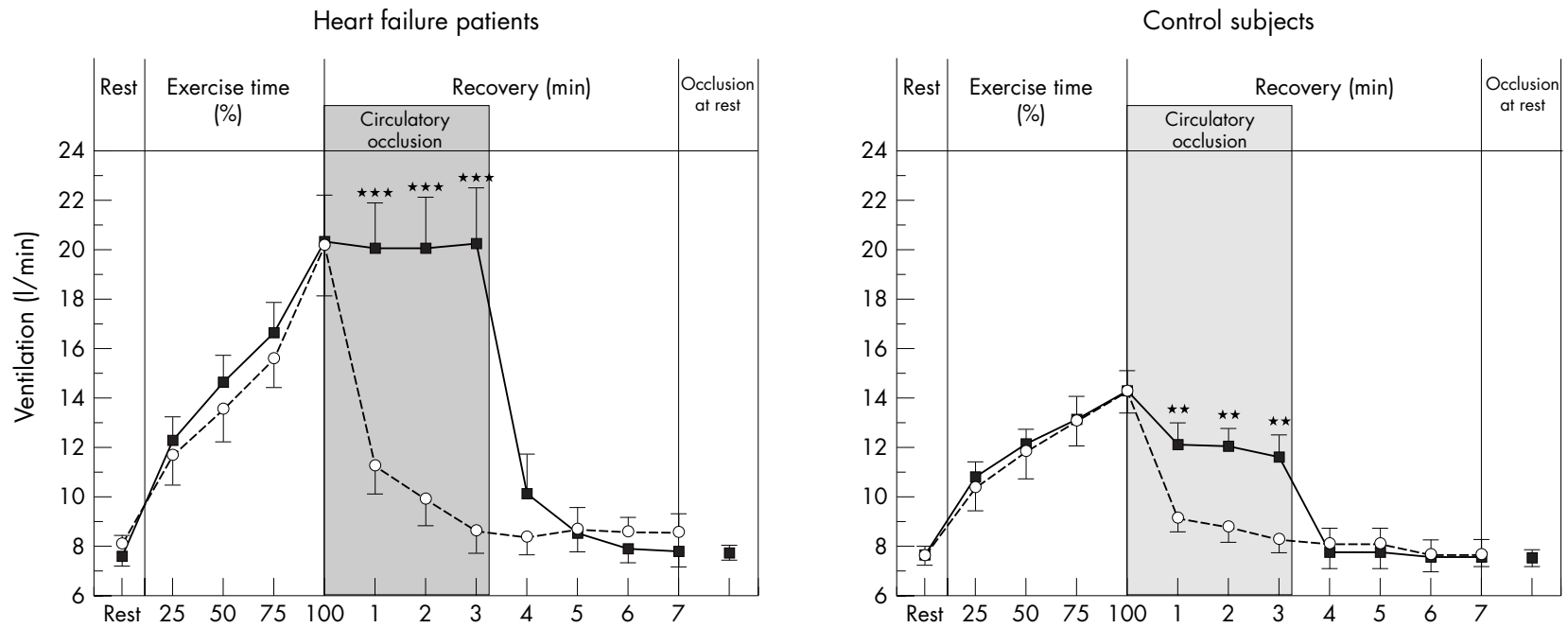

Figure 3 The ergoreflex in chronic HF. Handgrip dynamometer exercise to exhaustion finishes at the beginning of the shaded panel. A cuff is either inflated around the exercising arm at peak exercise (filled symbols, solid line) or not (open symbols, dotted line). The cuff is deflated after three minutes (end of shaded panel). Note that the patients with HF have a greater ventilatory response to exercise and that their ventilatory response is maintained at the same level as maximum exertion throughout the period of cuff inflation. Reproduced from Piepoli et al. ${ }^{25}$ 
unlikely to be affected by disuse, a systemic cause for the heart failure myopathy is likely.

\section{ANABOLIC-CATABOLIC IMBALANCE IN CHRONIC HEART FAILURE}

Far from being just a "haemodynamic" disease, heart failure is increasingly recognised to be a multisystem disease with changes in most body systems studied. Cardiac cachexia has been recognised since the time of Hippocrates and has latterly been shown to be associated with a particularly poor outcome. ${ }^{28}$ As previously noted, muscle bulk is lost early in the course of heart failure and, indeed, excess weight is associated with improved survival. ${ }^{29}$ Weight loss affects all body compartments: lean tissue, fat, and bone. ${ }^{30}$

The cause of weight loss is not known, but there is a general change in the balance between catabolic and anabolic factors in the chronic heart failure syndrome. Thus, for example, mass sympathetic stimulation (as seen in heart failure) is catabolic, causes an increase in the basal metabolic rate, causes glycogenolysis both through a direct effect and through inhibition of insulin secretion and promotion of glucagon secretion, and causes lipolysis. ${ }^{31}$

Insulin is a vital anabolic hormone, and insulin resistance is common in patients with heart failure..$^{32}$ Insulin resistance is characterised by high circulating concentrations of insulin and normal fasting glucose. Insulin concentrations are higher in patients with heart failure with cachexia than in those without, and body mass index is related to the degree of insulin resistance. Similarly, the catabolic steroid cortisol can be grossly increased in untreated patients with chronic heart failure, and the anabolic steroid precursor dehydroepiandrosterone is low. Thus, the ratio of cortisol to dehydroepiandrosterone rises in patients with chronic heart failure, which correlates negatively with body mass index (the higher the body mass index, the lower the ratio of catabolic to anabolic steroid).

Growth hormone resistance is also common in chronic heart failure: patients (particularly with untreated fluid retention) have high concentrations of circulating growth hormone but relatively low concentrations of its effector hormone, insulin-like growth factor $1 .{ }^{33}$

The cause of the shift in anabolic-catabolic balance is not clear but is perhaps due to continuous, low grade haemodynamic stress. In common with most mammals, one of the primary evolutionary demands on humans was to respond to acute stress from the environment. In response to haemorrhage, for example, there is short lived sympathetic stimulation, renin-angiotensin system activation, and vasopressin release; catabolism predominates with lipolysis and glycogenolysis releasing energetic substrate. In contrast, in periods of rest, anabolism predominates with storage and repair being more active.

Chronic heart failure is a chronic, low grade environmental threat. It results in a chronic shift from anabolic processes to catabolic processes. This is seen as, for example, an increase in the basal metabolic rate of patients with heart failure. As the condition, and the stress, endure, so muscle performance worsens, thus resulting in symptoms of breathlessness and fatigue (fig 4).

\section{THERAPEUTIC IMPLICATIONS}

Many of the pharmacological treatments for chronic heart failure have limited effect on symptoms while improving prognosis. It is interesting to note, however, that both angiotensin converting enzyme inhibitors and $\beta$ adrenoceptor antagonists are associated with weight gain, or at least delay in weight loss. Interrupting the chronic stress response thus seems to allow some anabolism to take place. These effects are probably mostly at the level of fat and have little direct bearing on symptoms.

It will be interesting to see the results of studies examining the effects of device therapy, particularly biventricular pacing, on the ergoreflex and peripheral muscle, as well as on the $\dot{\mathrm{V}} \mathrm{E} / \dot{\mathrm{V}}_{\mathrm{CO}}$ slope.

Exercise training, however, does offer the possibility of improving symptoms. Despite very severe left ventricular dysfunction, some patients have normal exercise responses and no symptoms. ${ }^{1}$ The key things that differentiate these patients from their symptomatic peers is better preservation

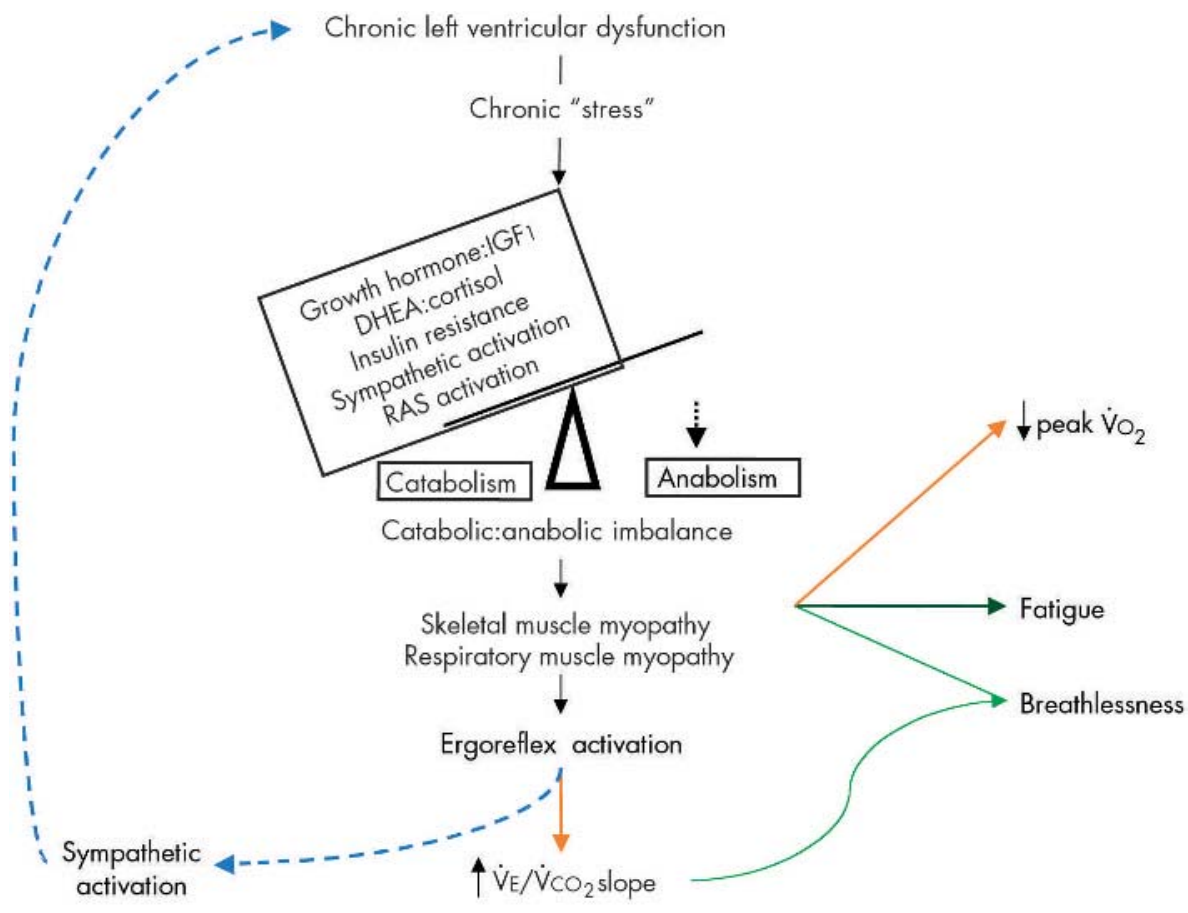

Figure 4 Origin of symptoms of chronic HF. Left ventricular impairment is a chronic stressor causing catabolic processes to predominate over anabolic. This leads to a skeletal myopathy, which generates fatigue, and in as much as it involves respiratory muscle, breathlessness. The myopathy causes enhanced ergoreflex activity, which in turn causes the increased $\dot{\mathrm{V}} \mathrm{E} / \dot{\mathrm{V}}_{\mathrm{CO}}$ slope, itself a cause of breathlessness. Ergoreflex activation also results in sympathetic activation, perhaps feeding back to worsen left ventricular function. DHEA, dehydroepiandrosterone; IGF1, insulinlike growth factor 1 ; RAS, reninangiotensin system; $\mathrm{VO}_{2}$, oxygen consumption. 
of leg muscle strength, bulk, and blood flow. Exercise training reduces ergoreflex activation and reduces the ventilatory response to exercise, as well as having numerous other benefits, such as a reduction in sympathetic activation and improved endothelial function..$^{25}$ Meta-analysis of the available data suggests that training regimens also probably improve prognosis. A comprehensive way to incorporate training packages into the routine care of patients with chronic heart failure has yet to be devised.

\section{REFERENCES}

1 Harrington D, Anker SD, Coats AJ. Preservation of exercise capacity and lack of peripheral changes in asymptomatic patients with severely impaired left ventricular function. Eur Heart J 2001 ;22:392-9.

2 Clark AL, Sparrow JL, Coats AJS. Muscle fatigue and dyspnoea in chronic heart failure: two sides of the same coin? Eur Heart J 1995; 16:49-52.

3 Witte KKA, Clark AL. Cycle exercise causes a lower ventilatory response to exercise in chronic heart failure. Heart 2005:91:225-6.

4 Ingle L, Shelton RJ, Rigby AS, et al. The reproducibility and sensitivity of the 6min walk test in elderly patients with chronic heart failure. Eur Heart $J$ 2005;26:1742-51.

5 Parameshwar J, Keegan J, Sparrow J, et al. Predictors of prognosis in severe chronic heart failure. Am Heart J 1992;123:421-6.

6 Buller NP, Poole-Wilson PA. Mechanism of the increased ventilatory response to exercise in patients with chronic heart failure. Br Heart $J$ 1990;63:281-3.

7 Franciosa JA, Park M, Levine TB. Lack of correlation between exercise capacity and indexes of resting left ventricular performance in heart failure. Am J Cardiol 1981;47:33-9.

8 Clark AL, Swan JW, Laney R, et al. The role of right and left ventricular function in the ventilatory response to exercise in chronic heart failure. Circulation 1994;89:2062-9.

9 Fink LI, Wilson JR, Ferraro N. Exercise ventilation and pulmonary artery wedge pressure in chronic stable congestive heart failure. Am J Cardio 1986;57:249-53

10 Marzo KP, Wilson JR, Mancini DM. Effects of cardiac transplantation on ventilatory response to exercise. Am J Cardiol 1992;69:547-53.

11 Jondeau G, Katz SD, Zohman L, et al. Active skeletal muscle mass and cardiopulmonary reserve: failure to attain peak aerobic capacity during maximal bicycle exercise in patients with severe congestive heart failure. Circulation 1992;86:1351-6.

12 Franciosa JA, Baker BJ, Seth L. Pulmonary versus systemic hemodynamics in determining exercise capacity of patients with chronic left ventricular failure. Am Heart J 1985; 1 10:807-13.

13 Clark AL, Coats AJS. Usefulness of arterial blood gas estimations during exercise in patients with chronic heart failure. Br Heart J 1994;71:528-30.

14 Sullivan MJ, Higginbotham MB, Cobb FR. Increased exercise ventilation in patients with chronic heart failure: intact ventilatory control despite haemodynamic and pulmonary abnormalities. Circulation 1988;77:552-9.
15 Puri S, Baker BL, Dutka DP, et al. Reduced alveolar-capillary membrane diffusing capacity in chronic heart failure. Circulation 1995;91:2769-74.

16 Clark AL, Volterrani M, Swan JW, et al. Increased ventilatory response to exercise in chronic heart failure: relation to pulmonary pathology. Heart 1997:77:138-46

17 Mohensifar Z, Amin DK, Shah PK. Regional distribution of lung perfusion and ventilation in patients with chronic congestive heart failure and its relationship to cardiopulmonary hemodynamics. Am Heart J 1989;1 17:887-91.

18 Volterrani M, Clark AL, Ludman PF, et al. Determinants of exercise capacity in chronic heart failure. Eur Heart J 1994; 15:801-9.

19 Buller NP, Jones D, Poole-Wilson PA. Direct measurements of skeletal muscle fatigue in patients with chronic heart failure. Br Heart J 1991;65:20-4.

20 Minotti JR, Pillay P, Chang L, et al. Neurophysiological assessment of skeletal muscle fatigue in patients with congestive heart failure. Circulation 1992:86:903-8.

21 Mancini DM, Coyle E, Coggan A, et al. Contribution of intrinsic skeletal muscle changes to 31P NMR skeletal muscle abnormalities in patients with chronic heart failure. Circulation 1989:80:1338-46.

22 Sullivan MJ, Green HJ, Cobb FR. Skeletal muscle biochemistry and histology in ambulatory patients with long-term heart failure. Circulation 1990;81:518-27

23 Massie BM, Conway M, Yonge R, et al. Skeletal muscle metabolism in patients with congestive heart failure: relation to clinical severity and blood flow. Circulation 1987;76:1009-19.

24 Clark AL, Piepoli M, Coats AJS. Skeletal muscle and the control of ventilation on exercise: evidence for metabolic receptors. Eur J Clin Invest 1995; 25:299-305

25 Piepoli M, Clark AL, Volterrani M, et al. Contribution of muscle afferents to the hemodynamic, autonomic, and ventilatory responses to exercise in patients with chronic heart failure: effects of physical training. Circulation 1996:93:940-52.

26 Clark AL, Volterrani M, Swan JW, et al. Leg blood flow, metabolism and exercise capacity in chronic stable heart failure. Int I Cardiol 1996;55:127-35

27 Wilson JR, Mancini DM, Dunkman WB. Exertional fatigue due to skeletal muscle dysfunction in patients with heart failure. Circulation 1993;87:470-5.

28 Anker S, Ponikowski P, Varney S, et al. Wasting as an independent risk factor for mortality in chronic heart failure. Lancet 1997;349:1050-3.

29 Davos CH, Doehner W, Rauchhaus M, et al. Body mass and survival in patients with chronic heart failure without cachexia: the importance of obesity. J Card Fail 2003:9:29-35

30 Anker SD, Clark AL, Teixeira MM, et al. Loss of bone mineral in patients with cachexia due to chronic heart failure. Am J Cardiol 1999;83:612-5.

31 Simonsen L, Bulow J, Madsen J, et al. Thermogenic response to epinephrine in the forearm and abdominal subcutaneous adipose tissue. Am J Physiol 1992;263:E850-5.

32 Swan JW, Anker SD, Walton C, et al. Insulin resistance in chronic heart failure: relation to severity and aetiology of heart failure. J Am Coll Cardiol 1997;30:527-32.

33 Niebauer J, Pflaum C-D, Clark AL, et al. Deficient insulin-like growth factor-l in chronic heart failure predicts altered body composition, anabolic deficiency, cytokine and neurohormonal activation. J Am Coll Cardiol 1998;32:393-7.

\section{bmjupdates+}

bmjupdates+ is a unique and free alerting service, designed to keep you up to date with the medical literature that is truly important to your practice.

bmjupdates+ will alert you to important new research and will provide you with the best new evidence concerning important advances in health care, tailored to your medical interests and time demands.

Where does the information come from?

bmjupdates+ applies an expert critical appraisal filter to over 100 top medical journals A panel of over 2000 physicians find the few 'must read' studies for each area of clinical interest

Sign up to receive your tailored email alerts, searching access and more...

www.bmjupdates.com 